\title{
Pinus Roxburghii Sarg. Ameliorates Alzheimer's disease- Type Neurodegeneration and Cognitive Deficits Caused by Intracerebroventricular-Streptozotocin in Rats: An In Vitro and In Vivo Study
}

\author{
L. SHARMA*, ADITI SHARMA, R. GOYAL AND J. ALAM ${ }^{1}$
}

School of Pharmaceutical Sciences, Shoolini University, Solan, H.P.-173229, ${ }^{1}$ Divison of Pharmacology and Toxicology, Indian Veterinary Research Institute, Izatnagar, Bareilly, UP-243122, India

Sharma et al.: Neuroprotective activity of Pinus roxburghii Sarg

\begin{abstract}
Pinus roxburghii Sarg. is traditionally used as a nerve tonic, hemostatic and anticonvulsant. The present study was aimed to investigate the neuroprotective activity of Pinus roxburghii Sarg. stem bark for memory and cognition using in vitro and in vivo methods. Plant drug was extracted with methanol using Soxhlet extraction. In vitro cell viability activity of Pinus roxburghii Sarg. was assessed using PC-12 cell lines. The in vivo neuroprotective activity of Pinus roxburghii Sarg. was tested on Wistar albino rats (either sex) and intracerebroventricular streptozotocin $(3 \mathrm{mg} / \mathrm{kg}$, bilateral) was given to cause memory deficits. High-performance thin layer chromatography fingerprinting was performed for the presence of quercetin and gallic acid in the plant extract. The phytochemical testing of extract revealed the presence of flavonoids, alkaloids, steroids, and tannins. Pinus roxburghii Sarg. showed significant cell viability at 10,50 and $100 \mu \mathrm{g} / \mathrm{ml}$ in an in vitro test on PC-12 cell lines. In the in vivo activity, intracerebroventricular streptozotocin caused significant deterioration in memory and cognition, tissue oxidative stress and acetylcholinesterase activity. Pinus roxburghii Sarg. 100, 200 and $300 \mathrm{mg} / \mathrm{kg}$, per os and donepezil $(3 \mathrm{mg} / \mathrm{kg}$, per os) significantly $(\mathrm{p}<0.05)$ reversed the behavioral changes in rats when tested on morris water maze and elevated plus maze. Increased levels of lipid peroxidation, acetylcholinesterase activity and decreased the level of glutathione were significantly $(\mathrm{p}<0.05)$ antagonized by Pinus roxburghii Sarg., similar to donepezil in rat brain. Quercetin and gallic acid were identified quantitatively in the plant extract in High-performance thin layer chromatography study. The methanolic extract of Pinus roxburghii Sarg. ameliorated intracerebroventricular streptozotocin induced cognitive deficits and memory impairment possibly due to the presence of quercetin and gallic acid.
\end{abstract}

Key words: Pinus roxburghii, Intracerebroventricular, Streptozotocin, Cognition, Dementia

Alzheimer's disease (AD), a progressive neurodegenerative disease, is characterized by impairment of cognitive functions and changes in behavioral activities following a slow and progressive deterioration of short-term memory. AD, pathologically, is known to be associated primarily with degeneration of the neurons due to release of neurotoxic protein amyloid and its accumulation and deposition between synapses and destabilization of the axons structure due to hyper phosphorylation of tau and related proteins ${ }^{[1-6]}$ and secondary, with generation of reactive oxygen species, nitric oxide radicals following mitochondrial dysfunction and vascular abnormalities ${ }^{[7-10]}$. Mostly present $\mathrm{AD}$ treating medications are based on the

*Address for correspondence

E-mail: lalitluckysharma88@gmail.com cholinergic hypothesis. Cholinergic hypothesis is known for the decreased neurotransmission levels in the brain due to cleavage of neurotransmitter acetylcholine (ACh) by enzyme acetylcholinesterase $(\mathrm{AChE})^{[11-13]}$. These regimens are just providing symptomatic relief where Alzheimer Association survey reported that approximately 35 million people worldwide are suffering from this disease and the

This is an open access article distributed under the terms of the Creative Commons Attribution-NonCommercial-ShareAlike 3.0 License, which allows others to remix, tweak, and build upon the work non-commercially, as long as the author is credited and the new creations are licensed under the identical terms

Accepted 15 October 2020

Revised 11 September 2020

Received 06 April 2020

Indian J Pharm Sci 2020;82(5):861-870 
rate of deaths for cardiac diseases decreased by $9 \%$ while death rate for $\mathrm{AD}$ has been increased by $145 \%$. These medications have also undesired effects in longterm assessment in AD patients ${ }^{[14-16]}$. The management of dementia and $\mathrm{AD}$ patients in advancing age with caregivers has become an economic burden. Hence, for the management and to arrest the chronic consequences of $\mathrm{AD}$, there is a need to search for the alternative options which may be approached with the use of herbal principles from medicinal plants documented for CNS problems ${ }^{[17,18]}$. Intra-cerebro ventricular administration of streptozotocin (ICVSTZ) is a method which produces symptoms of ADtype dementia in rodents and has been widely used for pre-clinically studies. ICV-STZ specifically causes oxidative stress, neuronal cell damage, cognitive impairments and memory loss paving the way to the clinical relevance of the experimental model to the symptoms of $\mathrm{AD}^{[19]}$.

Pinus roxburghii Sarg. generally known as Pine from family "Pinaceae", is an important resin and timberyielding plant species which obtained from northwestern Himalayan region. It is an Indian medicinal herb and traditionally described in an ethno-medical literature to use as nerve tonic and practice in memory problems and convulsion. It has been formulated into an Ayurvedic medicine to treat brain disorders. It has also reported to possess anti-oxidant, anti-inflammatory, anti-convulsant, anti-pyretic, anti-dyslipidemic and hepatoprotective activities ${ }^{[20]}$. P. roxburghii is known as a rich source of terpenoids, flavonoids, tannins and xanthones with mainly quercetin, gallic acid, $\alpha$-pinene and sitosterol components. Its chief constituent quercetin, a flavonoid has been reported to attenuate amyloid-induced cytotoxicity, protein oxidation, lipid peroxidation and apoptosis in hippocampal cultures. Gallic acid, another most abundant component of the plant, has been reported to reduce the neural damage by acting on oxidative and inflammatory cascades in neurodegenerative condition ${ }^{[21]}$. Gallic acid has also been found to protect the brain tissues against calcium excitotoxicity due to calcium accumulation, a source of glutamate-inducing neuronal apoptosis ${ }^{[22]}$. Literature reports that the major constituents of the plant, viz. quercetin, $\alpha$-pinene, catechin, friedelan and betasitosterol are active anti-AChE inhibitors ${ }^{[23]}$. Therefore, the present study was designed to investigate the neuroprotective effects of $P$. roxburghii stem bark extract employing in-vitro and in vivo methods.

\section{MATERIALS AND METHODS}

\section{Plant material, extraction and preliminary phytochemical screening:}

The stem bark of $P$. roxburghii was collected from hilly areas of the district, Solan, Himachal Pradesh, India with GPS coordinates $30.9045^{\circ} \mathrm{N}, 77.0967^{\circ} \mathrm{E}$ and duly authenticated at Y.S. Parmar University of Horticulture \& Forestry, Nauni, Solan. A voucher specimen with no. 12471 has been linked to field book of the institutional herbarium. The plant parts were dried in shade, pulverized and coarsely powdered to mesh size 20. The plant drug was defatted with petroleum ether and extracted with methanol (95\%) using soxhlet apparatus for $48 \mathrm{~h}$. Excess solvent was distilled slowly; the concentrate was dried in vacuo and kept in a refrigerator till further use. The methanolic extract of $P$. roxburghii was subjected to phytochemical screening for the presence of chemical constituents like alkaloids (Dragendroff's reagent and Hager's reagent), flavonoids (Shinoda test, zinc hydrochloride test and alkaline reagent test), Steroids \& triterpenoids (Salkowski test), carbohydrates (Molisch's test), Coumarin glycosides (Coumarin glycoside test), amino acids (Millon's test and ninhydrin test) and tannins (Ferric chloride test) ${ }^{[24]}$.

\section{Quantification of Quercetin and Gallic acid by High- performance thin layer chromatography (HPTLC):}

A flavonoid, Quercetin and phenolic constituent, Gallic acid were quantified in the methanolic extract of P. roxburghii using HPTLC instrument with CAMAG Linomat $\mathrm{V}$ automatic sample applicator, Thin layer radiochromatograph (TLC) scanner III, Camag twin trough chamber $10 \times 10 \mathrm{~cm}$, and WinCATS software in present study. Silica gel precoated 60 F254 glass plates $(10 \times 10 \mathrm{~cm}$ with $200 \mu \mathrm{m}$ thickness HPTLC; Merck $\mathrm{KGaA}$ ) were saturated for $20 \mathrm{~min}$ in a glass chamber with the mobile phase of toluene: ethyl acetate: formic acid $(5: 4: 1, \mathrm{v} / \mathrm{v} / \mathrm{v})$. Methanolic extract (the sample, suspended in methanol $1 \mathrm{mg} / \mathrm{ml}$ ) and standard solutions (each $5 \mu \mathrm{L}$, suspended in methanol $1 \mathrm{mg} / \mathrm{ml}$ ) were applied in the form of a band having bandwidth $8 \mathrm{~mm}$; distance between the bands $14 \mathrm{~mm}$ and a constant application rate of $150 \mathrm{~nL} \mathrm{~s}^{-1}$ using a micro-syringe (500 $\mu \mathrm{l}$ size, Hamilton-Bonaduz Schweiz, Linomat syringe) to TLC plate. TLC plate was placed under the mobile phase in a glass developing chamber and ascending development was performed to a distance of $8 \mathrm{~cm}$. Consequent to the development, the air-dried 
plate was subjected to the densitometry scanning (slit dimensions: $6 \times 0.45$ at $254 \mathrm{~nm}$ ) by using TLC scanner operated in reflectance-absorbance mode ${ }^{[25]}$.

\section{In vitro cell viability assay using PC12 cell lines:}

Rat pheochromocytoma PC12(RRID:CVCL_0481)cell lines procured from national center for cell sciences, Pune, India were used to assess the ability of the testing agents to prevent streptozotocin-induced cytotoxicity. A Dulbecco's Modified Eagle's medium (DMEM) containing $10 \%$ fetal calf serum and $5 \%$ horse serum was used for growth of the cells. Cytotoxicity assay was carried out using 96-well plates containing $100 \mu \mathrm{l}$ of medium per well. Plating of cells was done in medium containing dialyzed serum. A day after tomorrow, plating medium was replaced with DMEM containing dialyzed serum and the test reagents then were added. The following day, determination of the cells viability was done in microliter dishes using a viable stain kit. The percentage cell viability was calculated using the formula, $\%$ Cell viability $=$ OD sample/OD control $\times 100$, where OD control is an optical density for untreated normal control cells, and the OD sample is an optical density for cells treated with extract. DMSO (less than $1 \%$ ) was taken as a vehicle control ${ }^{[26]}$.

\section{Acute toxicity study using OECD guidelines:}

The acute toxicity study of the methanolic extract of P. roxburghii was performed as per guidelines (423) of the Organization for Economic Corporation and Development (OECD). In present study, the methanolic extract of $P$. roxburghii was given at the dose 2000 and $5000 \mathrm{mg} / \mathrm{kg}$ orally. Wistar rats (either sex) body weight 220-260 $\mathrm{g}$ and age 18-20 w were employed. The assessments were done at $6,12,24,48,72 \mathrm{~h}$ and up to $14 \mathrm{~d}$ for behavioral activities (e.g. ataxia, straub tail, stereotype, catatonia, salivation, lacrimation, piloerection, pellet expulsion and urination) or any adverse event including mortality. The extract showed no side effects and even no mortality at 2000 and $5000 \mathrm{mg} / \mathrm{kg}$ doses. Hence, the doses of the extract at 100,200 and $300 \mathrm{mg} / \mathrm{kg}$ orally, were selected as therapeutic and safe dose during in vivo testing ${ }^{[27]}$.

\section{In vivo neuroprotective activity using ICV-STZ model in rat:}

\section{Experimental animals and ethical consideration}

Wistar Albino rats of either sex, body weight 220 $-260 \mathrm{~g}$, age $18-20 \mathrm{w}$ were procured from the Animal house, Shoolini University, Solan (Registration No. 1541/PO/a/11/CPCSEA). They were housed in polypropylene animal cages with Sparcobb corn granules as bedding material (from Sparconn life sciences, Bengaluru, India). The animals were maintained at temperature $25 \pm 5^{\circ}$, humidity $45 \pm 5 \%$, 12-12 h light/dark cycle and provided with food (using pellet chow diet) and water ad libitum. The experimental protocol was duly approved by the Institutional Animal Ethics Committee (IAEC), Shoolini University, Solan with vide protocol no. IAEC/SU-PHARM/12/023. The experimentation was conducted under Committee for the purpose of control and supervision of experiments on animals (CPCSEA) guidelines, New Delhi, India.

\section{Experimental protocol}

Animals were divided randomly into seven groups, each group comprising six animals $(n=6)$. The sample size in each group was determined from the literature relevant to the study. Where, group-I: received $0.3 \%$ Critical Micelle Concentration (CMC) as vehicle and served as normal control; group-II: treated with surgical operations only, served as sham control; group-III: received ICV administration of STZ on the 1st and 3rd $\mathrm{d}$ bilaterally in two divided doses and served as disease control; group-IV: received ICV-STZ and Donepezil (an acetylcholinesterase inhibitor) $3 \mathrm{mg} / \mathrm{kg}$ and served as standard; group-V, VI, and VII: received ICVSTZ and methanolic extract of $P$. roxburghii at doses 100,200 and $300 \mathrm{mg} / \mathrm{kg}$, p.o. respectively. Animals were anesthetized using ketamine $80 \mathrm{mg} / \mathrm{kg}$, i.p. and xylazine $10 \mathrm{mg} / \mathrm{kg}$, i.p. The Stereotaxic apparatus with coordinates: $0.8 \mathrm{~mm}$ posterior to bregma, $1.5 \mathrm{~mm}$ lateral to sagittal suture, $3.6 \mathrm{~mm}$ ventral from the surface of the brain was used for ICV injection. STZ was dissolved in citrate buffer $(\mathrm{pH}=4.4)$ and injected at $3 \mathrm{mg} / \mathrm{kg}$ bilaterally via ICV route in two divided doses, on 1 st and 3rd d. Dental cement with adhesive was applied to seal the skull and the wound was sutured. Povidone-iodine solution was applied for healing of wound, and post-operative care was monitored. The animals were housed individually in one cage during postoperative care till recovery of wound for 3-5 $\mathrm{d}^{[28,29]}$. On completion of the experimental protocol, the behavioral assessments were done to evaluate the performance of animals over different mazes. The animals were sacrificed by decapitation, a method for euthanasia recommended as per CPCSEA guidelines. The brain was isolated and homogenized for tissue biochemical estimations. 


\section{Behavioral assessments:}

\section{Morris water maze (MWM) test for contextual/ spatial memory}

The apparatus consisted of the circular water tank (called as maze) of diameter $120 \mathrm{~cm}$ and $60 \mathrm{~cm}$ depth, filled to a depth of $40 \mathrm{~cm}$ with $22^{\circ}$ water. Four points equally distributed along the perimeter of the tank serve as starting locations. The tank was divided into four equal quadrants and small platform $(9 \mathrm{~cm}$ diameter and $38 \mathrm{~cm}$ height) was located in the center of the target quadrant. The platform remains in the same position during the training days. The rat was released into the water facing its head towards the wall and latency to find the platform was recorded for maximum $2 \mathrm{~min}$. Animals usually receive 4 trials per days until they escaped on to the platform and observed from $\mathrm{d} 17^{\text {th }}$ to $20^{\text {th }[29,30]}$.

\section{Elevated plus maze (EPM) test for acquisition and retention of memory}

EPM consists of two opposite open arms $(50 \times 10 \mathrm{~cm})$ crossed with two closed arms of the same dimensions with $50 \mathrm{~cm}$ walls. The arms related to center square $(10 \times 10 \mathrm{~cm})$. The acquisition of memory was assessed on $20^{\text {th }} \mathrm{d}$ (for ITL) and $21^{\text {st }}$ (for RTL). Rats were placed individually at one end of one open arm facing away from the center square. Movement of animals in both the arms is noted in terms of initial transfer latency (ITL) on day one of the training periods i.e. $20^{\text {th }} \mathrm{d}$ and the time is taken by the rat to move from the open arm and enter into one of the closed arms. After $24 \mathrm{~h}$, the rats were again placed similarly on the open arm and retention transfer latency (RTL) was recorded ${ }^{[31]}$.

\section{Tissue biochemical estimations:}

\section{Estimation of lipid peroxidation}

The reaction mixture contains $0.1 \mathrm{ml}$ of tissue homogenate, $0.2 \mathrm{ml}$ of $8.1 \%$ sodium dodecyl sulfate (SDS), $1.5 \mathrm{ml}$ of $20 \%$ acetic acid and $1.5 \mathrm{ml}$ of $0.8 \%$ aqueous solution of thiobarbituric acid (TBA). The $\mathrm{pH}$ of $20 \%$ acetic acid was adjusted with $1 \mathrm{~N}$ sodium hydroxide $(\mathrm{NaOH})$ to 3.5 . The mixture was finally made up to $4.0 \mathrm{ml}$ with distilled water and heated at $95^{\circ}$ for $60 \mathrm{~min}$ on an oil bath. After cooling under tap water, $1.0 \mathrm{ml}$ of distilled water and $5.0 \mathrm{ml}$ of a mixture of n-butanol and pyridine $(15: 1 \mathrm{v} / \mathrm{v})$ were added. The mixture was shaken vigorously on a vortex mixer and centrifuged then at $2200 \mathrm{~g}$ for $5 \mathrm{~min}$. The absorbance of the organic layer (upper layer) was measured immediately at $532 \mathrm{~nm}$ using UV-Vis double beam spectrophotometer (Systronics 2202). The lipid peroxidation reaction was assessed in the form of nmol/ $\mathrm{mg}$ of tissue ${ }^{[32]}$.

\section{Estimation of Glutathione (GSH)}

The brain tissue homogenate was added with an equal volume of $20 \%$ trichloroacetic acid (TCA) containing $1 \mathrm{mM}$ Ethylenediaminetetraacetic acid (EDTA) to precipitate the tissue proteins. The mixture was allowed to stand for $10 \mathrm{~min}$ and centrifuged at $2000 \mathrm{rpm}$ for $10 \mathrm{~min}$. The supernatant $(200 \mu \mathrm{l})$ was then treated with $1.8 \mathrm{ml}$ of Ellman's reagent (5, 5'-dithio bis-2-nitrobenzoic acid, $0.1 \mathrm{mM}$ ) prepared in $0.3 \mathrm{M}$ phosphate buffer with $1 \%$ of sodium citrate solution. The absorbance of the solution was estimated at $412 \mathrm{~nm}$ against blank. The level of GSH was expressed as $\mu \mathrm{mol} / \mathrm{mg}$ of tissue ${ }^{[33]}$.

\section{Determination of AChE activity}

The brain was homogenized in $25 \mathrm{mM}$ phosphate buffer saline ( $\mathrm{pH} 7.4,100 \mathrm{mg}$ tissue/ml of phosphate buffered saline (PBS) with Polytron homogenizer at $2000 \mathrm{rpm}$ for $30 \mathrm{sec}$. The homogenate was then centrifuged at 20,000 g for $30 \mathrm{~min}$ and the supernatant was isolated. Briefly, $0.1 \mathrm{ml}$ of buffered Ellman's reagent (Dithiobis-(2-nitrobenzoic acid) (DTNB) $10 \mathrm{mM}$, sodium bicarbonate $\left.\left(\mathrm{NaHCO}_{3}\right) 15 \mathrm{mM}\right)$ was mixed with $3 \mathrm{ml}$ of PBS ( $25 \mathrm{mM}$, pH 7.4), $0.2 \mathrm{ml}$ of $75 \mathrm{mM}$ acetylthiocholine iodide and allowed to incubate for $20 \mathrm{~min}$ at room temperature. The supernatant $(20 \mu 1)$ was added to the mixture and optical density was measured at $412 \mathrm{~nm}$ within $5 \mathrm{~min}$ with unit percentage inhibition of $\mathrm{AChE}^{[34]}$. The enzyme inhibition (\%) was calculated from the rate of absorbance change with time $(\mathrm{V}=\mathrm{Abs} / \Delta \mathrm{t})$. Inhibition $(\%)=100$-Change of sample absorbance/Change of blank absorbanceX100.

\section{Statistical analysis:}

Each finding of the research was compiled and evaluated using one way ANOVA (Analysis of variance) for elevated plus maze and tissue biochemical estimations whereas two way ANOVA was used for Morris water maze followed by Bonferronie"s multiple comparison tests as post-hoc. Results were presented as a mean \pm standard deviation (SD) and " $p$ " value $<0.05$ was statistically significant. Graph Pad Prism version 5 software was used. 


\section{RESULTS AND DISCUSSION}

The stem bark was extracted with methanol and the yield was found to be $4.12 \% \mathrm{w} / \mathrm{w}$. The qualitative analyses revealed the presence of flavonoids, alkaloids, carbohydrate, coumarin glycosides, steroids, tannin, and phenolics (terpenoids). However, amino acids were found to be absent.

The phytoconstituent like quercetin and gallic acid were identified quantitatively in $P$. roxburghii methanolic extract. A calibration curve of standard marker quercetin and Gallic acid $(\mu \mathrm{g} / \mathrm{ml})$ vs. area under the curve (AU) was prepared using HPTLC. Quercetin was quantified by a linear progression analysis with the equation: $\mathrm{y}=1284.2 \mathrm{x}+612.9, \mathrm{R}^{2}=0.9859$; and gallic acid with the equation: $y=2467 x+3227.2, R^{2}=0.9735$ were carried out. The percentage yield of quercetin was $2.218 \% \mathrm{w} / \mathrm{w}$ with $\mathrm{Rf}$ value 0.44 and Gallic acid was $0.659 \%$ with Rf value 0.35 in the methanolic extract of P. roxburghii. The HPTLC chromatograms were given in fig. 1(a), fig. 1(b) \& fig. 1(c).

The in vitro cytotoxicity assay was performed on PC-12 neuronal cell lines in triplicates $(n=3)$ and the methanolic extract of $P$. roxburghii reduced the streptozotocin-induced neuronal cell proliferation at $10,50,100$ and $150 \mu \mathrm{g} / \mathrm{ml}$. The results are presented in fig. 2.
In the MWM test, ICV-STZ administration to Wistar rats caused significant $(\mathrm{p}<0.05)$ deterioration of cognition and memory as evidenced by an increase in escape latency in comparison to normal untreated rats. The treatment with $P$. roxburghii extract at 100 , 200 and $300 \mathrm{mg} / \mathrm{kg}$ and donepezil $(3 \mathrm{mg} / \mathrm{kg}$ ) produced significant $(p<0.05)$ decrease in time to find the platform in the form of escape latency, as compared to ICV-STZ control animals (fig. 3).

In EPM test, administration of STZ through ICV route caused alterations related to memory or dementia in the form of increased time duration to enter in the closed arm as ITL, as compared to normal untreated rats on $\mathrm{d} 1$ of the training period. And the effect produced by the drug treatments was found to be insignificant in comparison to ICV-STZ on $\mathrm{d} 1$ of the training (fig. 3A). Whereas the ICV-STZ induced memory alterations were noted after $24 \mathrm{~h}$ as RTL_when compared to normal control. The administration of $P$. roxburghii extracts 100,200 and $300 \mathrm{mg} / \mathrm{kg}$ and donepezil $(3 \mathrm{mg} / \mathrm{kg}$ ) significantly $(\mathrm{p}<0.05)$ decreased RTL on $20^{\text {th }} \mathrm{d}$, as compared to ICV-STZ control [fig. 4(a) \& fig. 4(b)].

Brain tissue lipid peroxidation reactions and GSH level were estimated for oxidative stress caused due to STZ induced neurodegeneration and neuronal death. ICVSTZ control group showed a significant increase in
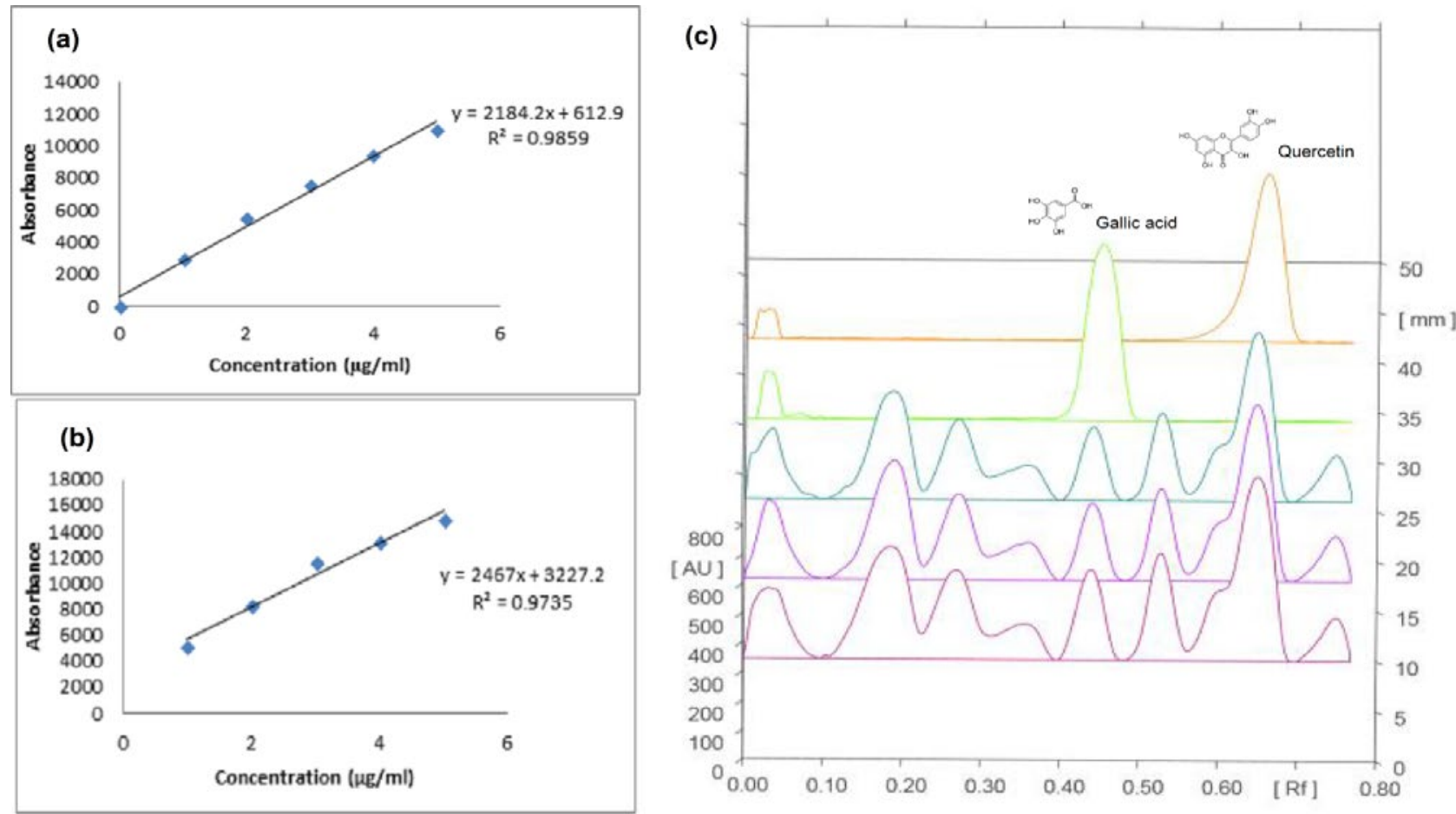

Fig. 1: Quantification of quercetin and gallic acid in Pinus roxburghii bark extract by HPTLC (a) Calibration curve for quercetin; (b) Calibration curve for gallic acid; (c) HPTLC chromatogram for Quercetin and gallic acid in methanolic extract of $P$. roxburghii. 
$(\mathrm{p}<0.05)$ lipid peroxidation $(428 \pm 38.0)$ and significant $(\mathrm{p}<0.05)$ decrease in GSH level in comparison to normal and sham control group. Administration of P. roxburghii 100, 200 and $300 \mathrm{mg} / \mathrm{kg}$ and donepezil caused significant $(\mathrm{p}<0.05)$ reversal of lipid peroxidation and GSH level, as compared to ICV-STZ group which may be due to the free radical scavenging and antioxidant property ${ }^{[35]}$ of the Pinus plant. [fig. 5(a) \& fig. 5(b)]

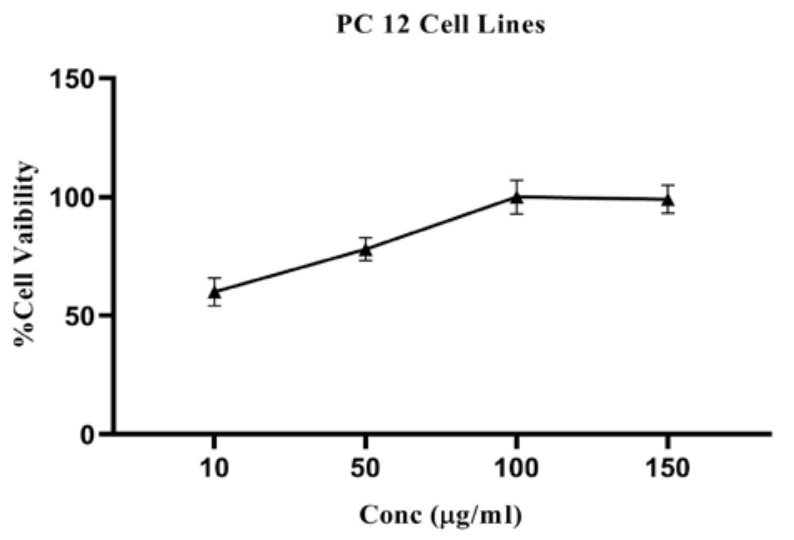

Fig. 2: In vitro \% cell viability of $P$. roxburghii extract using PC-12 cell lines at different concentrations. The data is expressed as the mean $\pm \operatorname{SEM}(n=3)$.
Assessment of AChE activity in brain homogenate showed significant $(p<0.05)$ increase in acetylcholinesterase activity in ICV-STZ control rats, as compared to normal control and sham group. Treatment with $P$. roxburghii extract $(100,200$ and $300 \mathrm{mg} / \mathrm{kg}$ ) and donepezil: $3 \mathrm{mg} / \mathrm{kg}$ significantly decreased cholinesterase activity, as compared to ICVSTZ group showing significant neuronal conduction via cholinergic neurons maintained by decreased decomposition of acetylcholine at the cleft responsible for memory cognition. [fig. 5(c)]

Impairment of cognition, learning and memory are the common and significant features of AD-type dementia. In the present study, ICV-STZ administration in rats induced impairment in memory. Rodents have presented the elevated levels of $\mathrm{AChE}$ activity, lipid peroxidation along with a significant decreased in the brain GSH levels. The observations of the present work are similar to the previous reports ${ }^{[36]}$. The rats administered with STZ have exhibited significant memory impairment and poor performances under the MWM investigations as it is an evident in the form of increased escape latency in ICV-STZ treated control ones on day twentieth. The animals were provided with training for 4 consecutive

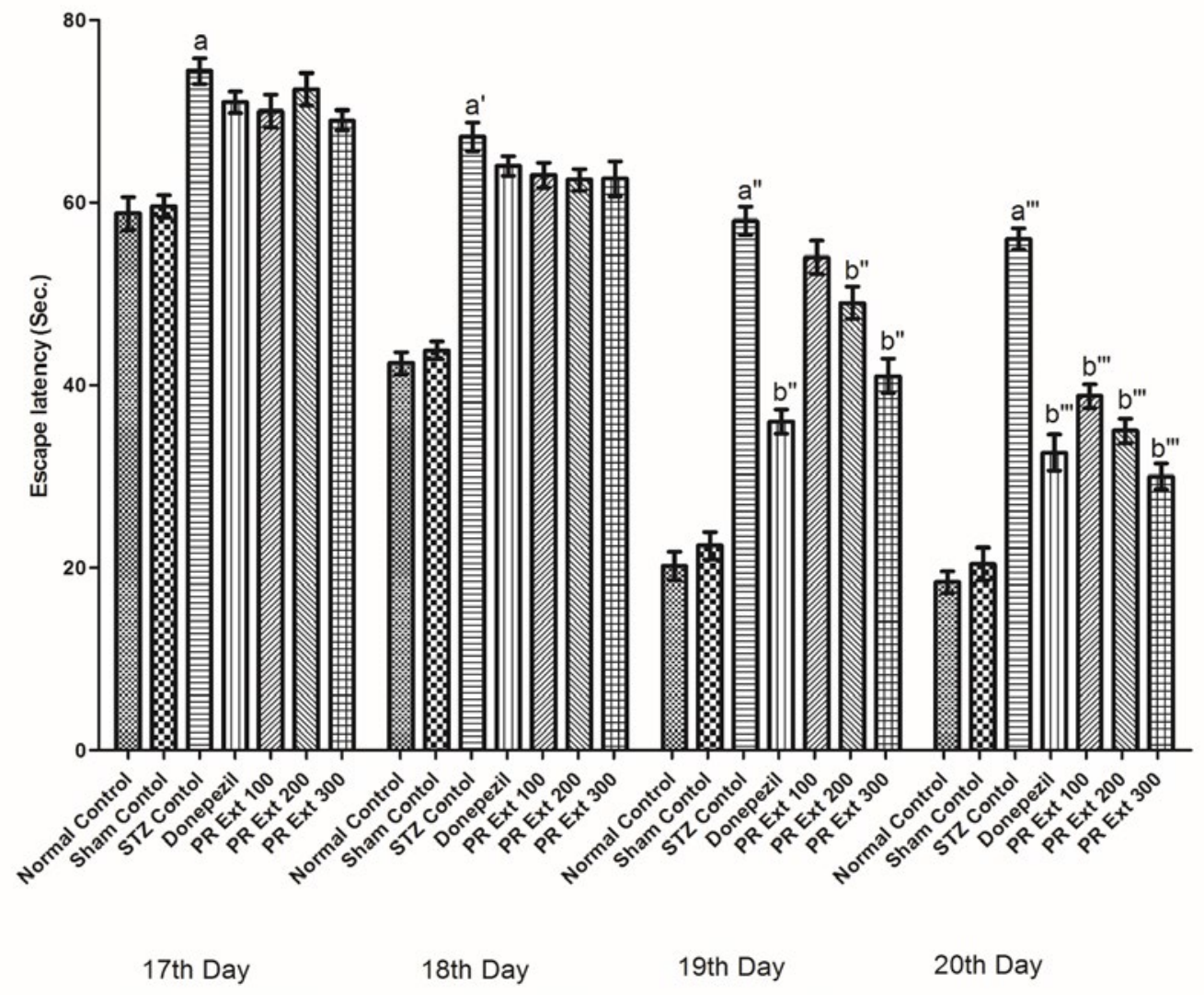

Fig. 3: Effect of drug treatment on contextual/spatial memory in MWM test; Results: mean \pm SD; (n=6); Two way ANOVA was used followed by Bonferronie"s multiple comparison test; a, a', a" and a"” $p<0.05$ vs. normal control on $17^{\text {th }}, 18^{\text {th }}, 19^{\text {th }}$ and $20^{\text {th }} d ; b^{\text {" }}$ and $b^{\text {"' }}$ p $<0.05$ vs. ICV-STZ on $19^{\text {th }}$ and $20^{\text {th }} d$. 
(a)

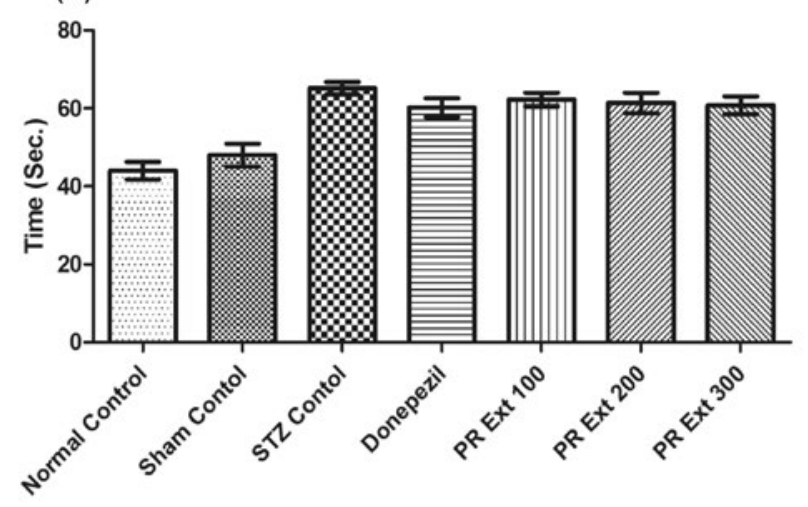

(b)

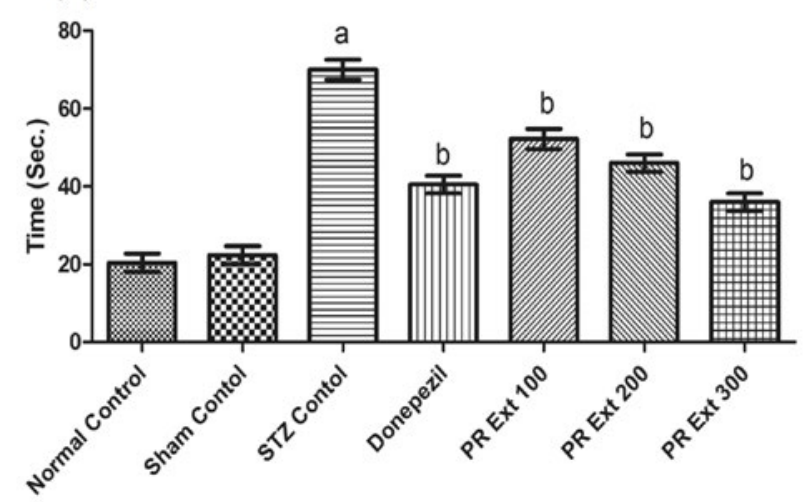

Fig. 4: Effect of drug treatment on acquisition and retention of memory on elevated plus maze test; 4(a) Initial transfer latency and 4(b) Retention transfer latency; Results: mean \pm SD; $(n=6)$; One way ANOVA was used followed by Bonferroniees multiple comparison test, ${ }^{a} p<0.05$ vs. normal control, ${ }^{b} p<0.05$ vs. ICVSTZ control. $\mathrm{d}$ in the MWM. Escape latency is assessed in the form of the time taken by the animal to find the platform or the time to escape from the water. The ICV-STZ treated rats were observed from the $\mathrm{d} 17^{\text {th }}$ to $20^{\text {th }}$ that showed a progressive increased in cognitive impairment. The performance of rats in EPM for memory cognition is well documented to estimate acquisition and retention of memory. Paradigm of the maze is in fashion to test the behavioral performance of animal to remember escape from the condition, after $1 \mathrm{~d}$ or $24 \mathrm{~h}$ training ${ }^{[29]}$. In this test, the rats were assessed for their performances on $\mathrm{d} 20^{\text {th }}$ as ITL and on $\mathrm{d} 21^{\text {st }}$ as RTL that was found to be increased after ICV-STZ treatment. This effect may be due to significant neurodegeneration, poor neuronal conduction via axon and synapse, and induced memoryincardination caused in the brain. Administration of $P$. roxburghii extract: 100, 200 and $300 \mathrm{mg} / \mathrm{kg}$ showed a significant decrease in escape latencies, in comparison to the ICV-STZ treated animals in MWM and a significant decrease in the RTL in EPM dosedependently, as compared to ICV-STZ control animals. Therefore, the effect of the plant extract in improving memory deficits may be due to its potential to prevent neurodegeneration, oxidative stress and increase cholinergic transmission. The methanolic extract was found to be safe in acute toxicity studies conducted as per OECD 423 guidelines given at the doses 2000 and $5000 \mathrm{mg} / \mathrm{kg}$ dosage characterizing the presence of safe bioactive constituents which may be responsible for

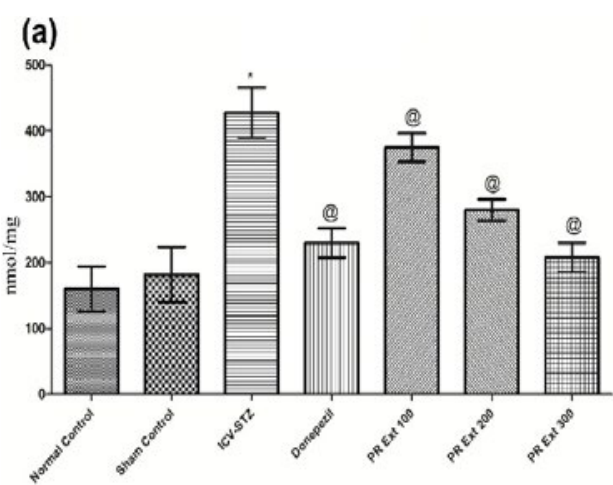

(b)
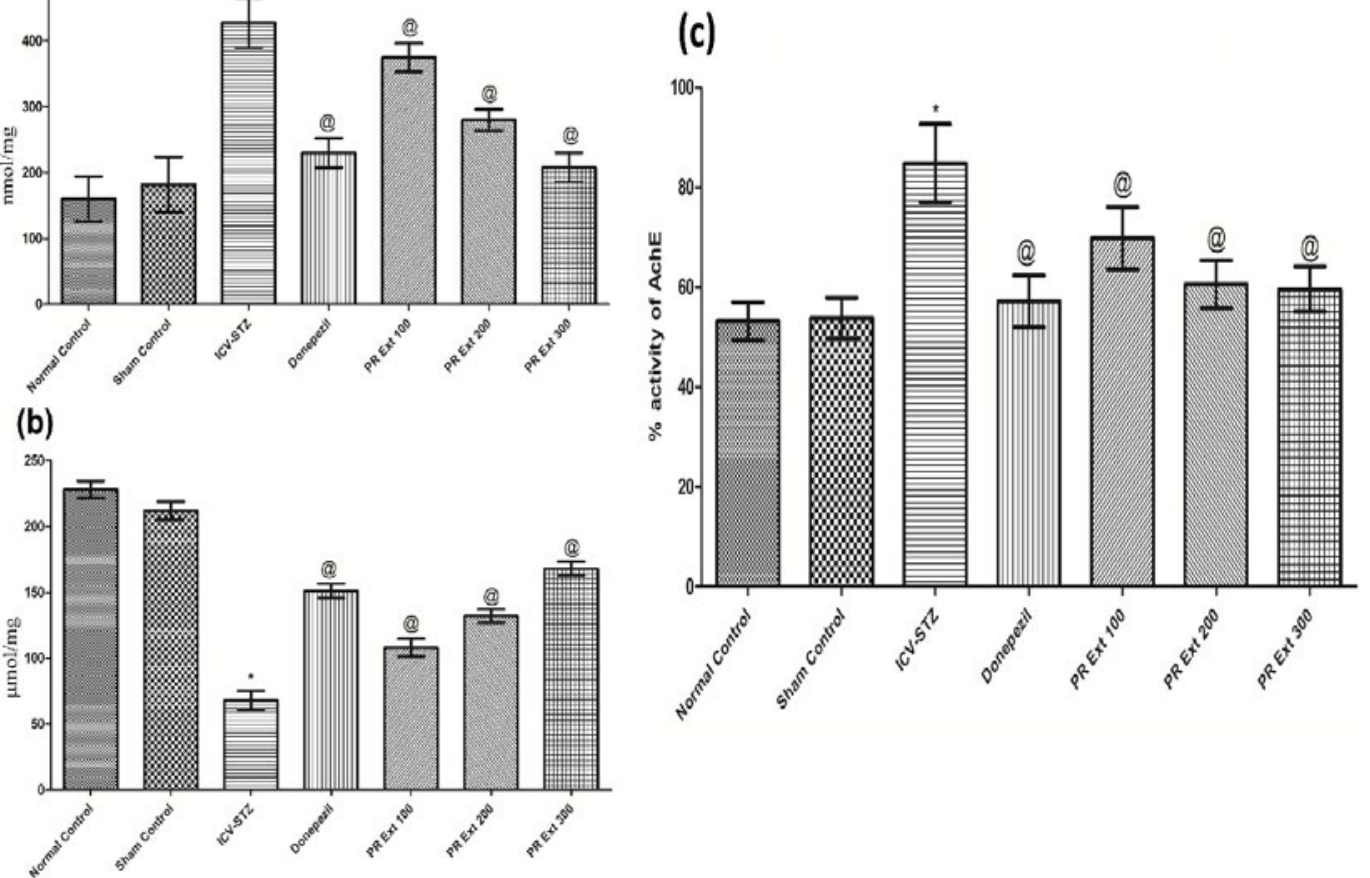

Fig. 5: Effect of drug treatment on brain tissue (a) lipid peroxidation; (b) glutathione levels; (C) AChE activity; Results: mean \pm SD, $(\mathrm{n}=6) * \mathbf{p}<0.05$ vs. Normal control, ${ }^{\circledR} \mathbf{p}<0.05$ vs ICV-STZ, PR=Pinus roxburghii mentioned with doses 100,200 and $300 \mathrm{mg} / \mathrm{kg}$. 
neuroprotective activity in the present study. ICV-STZ induced neurodegeneration is characterized by increased production of free radicals, which are highly unstable, short-lived and reactive to cause lipid peroxidation reaction forming lipid peroxides of neuronal membrane and further leads to increased pro- inflammatory mediators and mitochondrial dysfunction ${ }^{[37]}$. The lipid peroxidation reactions were found to be decreased significantly in brain tissue of ICV-STZ rats when treated with 100,200 , and $300 \mathrm{mg} / \mathrm{kg}$ of $P$. roxburghii, as compared to ICV-STZ rats. GSH, a tripeptide, is found in high concentrations in all cells and is involved in combating reactive oxygen species. In brain cells, GSH non-enzymatically reacts with radicals and detoxifies radicals like superoxide radical anion, nitric oxide or the hydroxyl radical. In another mechanism, GSH reduces peroxides in the glutathione peroxidase (GPx) reaction leading to the formation of glutathione disulfide which further regenerates GSH by transfer of electrons from nicotinamide adenine dinucleotide phosphate (reduced form, NADPH) ${ }^{[38]}$. The decreased level of GSH in ICV-STZ group is an indication of significant antioxidant depletion due to increased free radicals. Restoration of GSH activity observed on treatment with $P$. roxburghii extract 100, 200 and $300 \mathrm{mg} / \mathrm{kg}$ to ICV-STZ animals and this may be due to the ability of constituents of plant extract to scavenge free radicals and decrease in inflammatory reactions. Thus, these results represent that the stem bark of $P$. roxburghii has potent bioactive compounds that play key roles in neuroprotection and responsible for improving memory and cognition, and reducing the oxidative stress in the brain of rats. ICV administration of STZ causes reduction in cerebral energy metabolism, which leads to cognitive dysfunction by inhibiting the synthesis of adenosine triphosphate (ATP) and acetyl coenzyme A. This results into cholinergic deficiency supported by reduced choline acetyltransferase (ChAT) activity in hippocampus which further leads to comparative increased AChE activity in rat brain $^{[39,40]}$. The changes in AChE activity may be due to hyperglycemia like condition in the brain produced by STZ administration as it is reported that AChE activity is increased in serum and cerebral cortex in diabetic rats $^{[41]}$. This context is supported by findings of ICV-STZ group showing increased $\mathrm{AChE}$ activity. P. roxburghii in three doses significantly decreased the activity of AChE and thereby able to maintain the neurotransmission by improving acetylcholine levels in the brain which is responsible for cognitive and retentive abilities and resulting decrease in gene transcription, translation and enhance cholinergic activity. The results of in vitro cell viability assay on PC-12 cell lines present that P. roxburghii prevented cell proliferation and showed neuroprotective efficacy at concentrations 10,50 and $100 \mu \mathrm{g} / \mathrm{ml}$ that may be correlated to the nature of phenolic and flavonoid compounds of the extract. In this context, quercetin and gallic acid have been demonstrated, also identified in stem bark and inhibit neuronal toxicity and apoptosis by reversing mitochondrial dysfunction, free radical production ${ }^{[42,43]}$. The results from in vitro studies provide additional evidence for the protective effects of $P$. roxburghii in neurodegenerative disorders. The phytochemical screening of plant extract showed the presence of saponins, carbohydrates, flavonoids, tannins, steroids, and triterpenoids. On this basis, an HPTLC analysis of methanolic extract was carried out which revealed the presence of quercetin (flavonoid) and gallic acid (phenolic) in the methanolic extract. Quercetin is well emphasized in attenuating amyloid beta-induced cytotoxicity, protein oxidation, lipid peroxidation and apoptosis in brain cells ${ }^{[44]}$. Quercetin is also reported to decrease extracellular $\beta$-amyloidosis, tauopathy, astrogliosis and microgliosis and $\beta$-amyloid levels in hippocampus and amygdala ${ }^{[45]}$. Gallic acid also prevented glutamate-induced calcium deposition and reported for antioxidant action ${ }^{[20]}$. Gallic acid also inhibits oligomerization of $A \beta$ and improves cognitive functions. Moreover, catechin, sitosterol, and quercetin have been reported to possess potent anticholinesterases activity ${ }^{[46,47]}$. Moreover other species of Pinus like Pinus halepensis and Pinus massoniana are also reported to have anti-AD activity ${ }^{[48,49]}$. From the inferences of this study, the authors demonstrate that the supplementation of the extract of $P$. roxburghii stem bark potentially combated the cell proliferation in cell lines study and ameliorated the ICV-STZ induced alterations in behavioral, cognition, memory, biochemical and $\mathrm{AChE}$ expression in the hippocampus of rats. Although, our results significantly show the neuroprotective efficacy of the plant extract, but much more in vivo investigations are still needed for the clinical relevance of $P$. roxburghii.

\section{Acknowledgments:}

The authors are thankful to the management and head central instrumental facility of Shoolini University, Solan and for providing research facilities.

\section{Conflict of interests:}

The authors declared no conflicts of interest.. 


\section{REFERENCES}

1. Crimins JL, Pooler A, Polydoro M, Luebke JI, Spires-Jones TL. The intersection of amyloid beta and tau in glutamatergic synaptic dysfunction and collapse in Alzheimer's disease. Ageing Res Rev 2013;12(3):757-63.

2. Alam J, Sharma L. Potential Enzymatic Targets in Alzheimer's: A Comprehensive Review. Current drug targets 2019;20(3):316-39.

3. Ballard C, Gauthier S, Corbett A, Brayne C, Aarsland D, Jones E. Alzheimer's disease. Lancet 2011;377:1019-31.

4. Duthey B. Background paper 6.11: Alzheimer disease and other dementias. A public health approach to innovation 2013;6:1-74.

5. Alam J, Jaiswal V, Sharma L. Screening of Antibiotics against $\beta$-amyloid as Anti-amyloidogenic Agents: A Drug Repurposing Approach. Curr Comput Aided Drug Des 2020.

6. Kumar D, Sharma A, Sharma L. A comprehensive review of Alzheimer's association with related proteins: pathological role and therapeutic significance. Curr Neuropharmacol 2020;18(8):674-95.

7. Espinet C, Gonzalo H, Fleitas C, Menal MJ, Egea J. Oxidative stress and neurodegenerative diseases: a neurotrophic approach. Curr Drug Targets 2015;16(1):20-30.

8. Gibson GE, Huang HM. Oxidative stress in Alzheimer's disease. Neurobiol Aging 2005;26(5):575-8.

9. Sharma A, Goyal R, Sharma L. Potential biological efficacy of Pinus plant species against oxidative, inflammatory and microbial disorders. BMC Complement Altern Med 2015;16(1):35.

10. Sharma L, Sharma A. In vitro antioxidant, anti-inflammatory, and antimicrobial activity of hydro-alcoholic extract of roots of Withania somnifera. J Chem Pharm Res 2014; 6(7):178-82.

11. Aprahamian I, Stella F, Forlenza OV. New treatment strategies for Alzheimer's disease: is there a hope. IJMR 2013;138:44960.

12. Soreq H, Seidman S. Acetylcholinesterase- new roles for an old actor. Nature 2001;2: 294-302.

13. Craig LA, Hong NS,_McDonald RJ. Revisiting the cholinergic hypothesis in the development of Alzheimer's disease. Neurosci Biobehav Rev 2011;35:1397-409.

14. Bachurin SO, Bovina EV, Ustyugov AA. Drugs in Clinical Trials for Alzheimer 's disease: The Major Trends. Med Res Rev 2017;37:1186-225.

15. Casey DA, Antimisiaris D, and O'Brien J. Drugs for Alzheimer's disease: are they effective? P T 2010;35(4):20811.

16. Goodman LS. Goodman and Gilman's manual of pharmacology and therapeutics. Mcgraw Hill Professional 2008.

17. Tewari I, Sharma L, Gupta, GL. Synergistic antioxidant activity of three medicinal plants Hypericum perforatum, Bacopa monnieri, and Camellia sinensis. Indo Am J pharm res 2014;4(5):2563-8.

18. Sharma L, Sharma A, Gupta GL, Bisht GS. Protective effect of Ocimum sanctum Linn. leaf extract on ethanol withdrawal syndrome in Wistar rats. Asian Pac J Trop Med 2018;11(8):46772.

19. Grieb P. Intracerebroventricular Streptozotocin Injections as a Model of Alzheimer's disease: in Search of a Relevant Mechanism. Mol Neurobiol 2016;53(3):1741-52.

20. Sharma A, Sharma L, Goyal R. A review on Himalayan pine species: Ethnopharmacological, phytochemical and pharmacological aspects. Pharmacogn J 2018;10(4):611-19.
21. Hajipour S, Sarkaki A, Farbood Y, Eidi A, Mortazavi P, Valizadeh Z. Effect of Gallic Acid on Dementia Type of Alzheimer Disease in Rats: Electrophysiological and Histological Studies. Basic Clin Neurosci 2016;7(2):97-106.

22. Korani MS, Farbood Y, Sarkaki A, Moghaddam HF, Mansouri MT. Protective effects of gallic acid against chronic cerebral hypoperfusion-induced cognitive deficit and brain oxidative damage in rats. Eur J Pharmacol 2014;733:62-7.

23. Perry NS, Houghton PJ, Theobald A, Jenner P, Perry EK. In vitro inhibition of human erythrocyte acetylcholinesterase by salvia lavandulaefolia essential oil and constituent terpenes. J Pharm Pharmacol 2000;52(7):895-902.

24. Tewari P, Kumar B, Kaur M, Kaur G, Kaur H. Phytochemical screening, and Extraction: A Review. I Pharm Sciencia 2011;1(1):98-106.

25. Bhole RP, Shinde SS, Chitlange SS, Wankhede SB. A HighPerformance Thin Layer Chromatography (HPTLC) Method for Simultaneous Determination of Diphenhydramine Hydrochloride and Naproxen Sodium in Tablets. Anal Chem Insights 2015;10:47-51.

26. Behl C, Davis JB, Lesley R, Schubert D. Hydrogen peroxide mediates amyloid beta protein toxicity. Cell 1994;77(6):81727.

27. Sharma L, Sharma A, Gupta GL, Bisht GS. Acute and Subacute Oral Toxicity Assessment of a Standardized Polyherbal Preparation POL-6 in Rats. Nat Prod J 2019;9(3):207-16.

28. Sonkusare S, Srinivasan K, Kaul C, Ramarao P. Effect of donepezil and lercanidipine on memory impairment induced by intracerebroventricular streptozotocin in rats. Life Sci 2005;77(1):1-14.

29. Vishwakarma S, Goyal R, Gupta V, Dhar KL. GABAergic effect of Valeric acid from Valeriana wallichii in amelioration of ICV STZ induced dementia in rats. Rev Bras Farmacogn 2015;26(4):484-9.

30. Vorhees CV, Williams MT. Morris water maze: procedures for assessing spatial and related forms of learning and memory. Nat Protoc 2006;1(2):848-58.

31. Sharma AC, Kulkarni SK. Evaluation of learning and memory mechanisms employing plus maze in rats and mice. Prog Neuropsychopharmacol Biol Psychiatry 2006;16(1):117-25.

32. Ohkawa H, Ohishi N, Yagi K. Assay for lipid peroxides in animal tissues by thiobarbituric acid reaction. Anal Biochem 1979;95(2):351-8.

33. Ellman GL. Tissue sulphydryl groups. Arch Biochem Biophys 1959;82(1):70-7.

34. Ellman GL, Courtney KD, Andres Jr V, Featherstone RM. Anew and rapid colorimetric determination of acetylcholinesterase activity. Biochem Pharmacol 1961;7(2):88-95.

35. Zhao Y, Zhao B. Oxidative Stress and the Pathogenesis of Alzheimer's disease. Oxid Med Cell Longev 2013; 2013:1-10.

36. Sharma M, Gupta YK. Intracerebroventricular injection of streptozotocin in rats produces both oxidative stress in the brain and cognitive impairment. Life Sci 2001;68(9):1021-29.

37. Khare M, Mohanty C, Das BK, Jyoti A, Mukhopadhyay B, Mishra SP. Free radicals and antioxidant status in protein energy malnutrition. Int J Pediatr 2014;2014:254-396.

38. Dringen R. Metabolism and functions of glutathione in brain. Prog Neurobiol 2000;62(6):649-71.

39. Prickaerts J, Fahrig T, Blokland A. Cognitive performance and biochemical markers in septum, hippocampus, and striatum of rats after an icv injection of streptozotocin: a correlation analysis. Behav Brain Res 1999;102(1-2):73-88.

40. Sanchez-Chavez G, Salceda R. Effect of streptozotocin- 
induced diabetes on activities of cholinesterases in the rat retina. IUBMB Life 2002;49(4):283-7.

41. Mogana R, Adhikari A, Debnath S, Hazra S, Hazra B, TengJin $\mathrm{K}$, et al. The antiacetylcholinesterase and antileishmanial activities of Canarium patentinervium Miq. Biomed Res Int 2014; 2014:1-7.

42. Shen YC, Juan CW, Lin CS, Chen CC, Chang CL. Neuroprotective effect of terminalia chebula extracts and ellagic acid in pc12 cells. Afr J Tradit Complement Altern Med 2017;14(4):22-30.

43. Espargaró A, Ginex T, Vadell MD, Busquets MA, Estelrich J, Muñoz-Torrero D, et al. Combined in Vitro Cell-Based/ in Silico Screening of Naturally Occurring Flavonoids and Phenolic Compounds as Potential Anti-Alzheimer Drugs. J Nat Prod 2017;24(2):278-89.

44. Ansari MA, Abdul HM, Joshi G, Opii WO, Butterfield DA. Protective Effect of Quercetin in Primary Neurons against A $\beta$ (1-42): Relevance to Alzheimer's disease. J Nutr Biochem 2009;20(4):269-75.

45. Sabogal-Guaqueta MA, Munoz-Manco JI, Ramirez-Pineda JR, Lamprea-Rodriguez M, Osorio E, Cardona-Gomez GP.
The flavonoid quercetin ameliorates Alzheimer's disease pathology and protects cognitive and emotional function in aged triple transgenic Alzheimer's disease model mice. Neuropharmacology 2015;93:134-45.

46. Kolak U, Hacibekiroglu I, Ozturk M, Ozgokce F, Topcu G, Ulubelen A. Antioxidant and anticholinesterase constituents of Salviapoculata. Turk J Chem 2009;33:813-23.

47. Orhan I, Kartal M, Tosun F, Sener B. Screening of various phenolic acids and flavonoid derivatives for their anticholinesterase potential. Z Naturforsch C 2007;62(1112):829-32.

48. Postu PA, Sadiki FZ, Idrissi ME, Cioanca O, Trifan A, Hancianu M, et al. Pinus halepensis essential oil attenuates the toxic Alzheimer's amyloid beta (1-42)-induced memory impairment and oxidative stress in the rat hippocampus. Biomed Pharmacother 2019;112;108673.

49. Wang C, He L, Yan M, Zheng GY, Liu XY. Effects of polyprenols from pine needles of Pinus massoniana on ameliorating cognitive impairment in a D-galactose-induced mouse model. Age 2014;36(4):9676. 